\title{
Integrating African Indigenous Knowledge in Kenya's Formal Education System: The Potential for Sustainable Development
}

\author{
Jenipher A. Owuor \\ University of British Columbia \\ jaowuor@yahoo.com
}

\begin{abstract}
The current paradigm shift toward promoting education for sustainable development gravitates toward alternative approaches to school curricula in Sub-Saharan Africa. It is argued that solutions to problems that currently plague the continent and with reference to the Kenyan context must proceed from understanding of local capacities such as the role of indigenous knowledge in promoting sustainable development. This can be achieved by integrating indigenous knowledge into the formal education system to address some of the knowledge deficiencies for development that is currently formulated from the western perspective. This approach challenges the dominance of western knowledge in Kenya's school system that makes education disembodied from context. The purpose of this paper is to explore the meaning of indigenous knowledge, provide rationale for valuing indigenous knowledge in formal school system, examine the government's efforts to indigenise curricula, and dilemmas to integrating indigenous knowledge in formal education with implications to teacher education programs.
\end{abstract}

\section{Introduction}

The current paradigm shift towards promoting Education for Sustainable Development (ESD) gravitates toward alternative approaches to school curricula in Sub-Saharan Africa. There is now a growing consensus that some of the solutions to problems that currently plague African societies and communities must proceed from understanding the dynamics within the local context. Such dynamics include the role of indigenous knowledge and practices in the development processes (Angioni, 2003; Dei, 2002; Republic of Kenya, 2005; UNESCO, 2006). The strategy requires the adoption of an endogenous approach to education that involves the contextualization of the school curriculum by integrating indigenous knowledge with other relevant and useful knowledges into formal education. This is summed up in a UNESCO (2006) document as follows; "it is especially an attempt to promote education for sustainable development of African societies where cultures and ways of life are balanced with global and international pressures and demands" (p. 6). Education is therefore, acknowledged as being instrumental in harmonizing the different forms of knowledge bases and creating a social fabric for societies that can engender social, economic, and political sustainability.

The current dominating discourse on indigenous knowledge in the Kenyan education context for instance arises from the recognition of the need to address deficiencies of knowledge of development that is formulated in western contexts. With the integration of local knowledge that is more appropriate to the needs of the indigenous

Journal of Contemporary Issues in Education, 2007, 2(2), pp. 21-37.

ISSN 1718-4770 (C) 2007 University of Alberta

http://ejournals.library.ualberta.ca/index.php/JCIE 
communities it is hoped that local problems can be addressed effectively. Since the 1970s a growing number of scholars and United Nations organizations turned their attention to exploring how indigenous knowledge and institutions could contribute to more culturally appropriate and sustainable development (Dei, 2002; Mwenda, 2003; Shiva, 2003; UNESCO, 2006). It has been realized that indigenous people are not only more aware of but also better able to identify their own needs than are outside developers. More so that those needs are culturally defined as ways in which the survival of indigenous peoples depend upon significantly (Dei, 2002; Mudimbe, 1988). Thus, the objective of endogenous approach to education is to enable Sub-Saharan African countries such as Kenya to develop the capacity to redefine their own paradigm of development based on diverse contexts of the local communities (Angioni, 2003; Dei, 2002; Mudimbe, 1988; Shiva, 2002; Purcell, 1998). The assumption is that by creating awareness of the value and potential contribution of indigenous knowledge and practices to sustainable development, Kenya and other African countries would be able to realize alternative solutions to current pressing issues such as alleviating poverty and the challenges attributed to HIV/AIDS pandemic at grassroots levels.

Dei asserts that "we need to call for locally defined models of sustainability in which will prevail the realities of local peoples, with all their societal, cultural, political, spiritual, moral, and ecological goals and aspirations" (p. 12). An endogenous approach to education is multifaceted and places among other factors environmental preservation practices as key to sustainable development. Thus, communities can be able to build their social and cultural capital in order to exercise their sovereignty in their own development processes. The idea is to set up appropriate institutional spaces for communities and educators to provide guidance to socio-economic development through multiple forms of knowledge including indigenous knowledge forms and pedagogies. Through this approach it is hoped that communities will be able to self-organize and selfdirect skills and knowledge that can support development at the micro level (Dei, 2002; Mwenda, 2003; Shiva, 2003; UNESCO, 2006) in order to avert the current economic marginalization facing African countries such as Kenya.

The challenges facing African states such as Kenya is the capacity to define their own paradigm of development if they are to expand their own locus of authority out of the web of dependency on developed nations created by many years of colonial and foreign influence on education and development policies (Mwenda, 2003; Republic of Kenya, 2005). Therefore, the focus of an endogenous approach to education in Kenya should involve the following goals. First it should aim to enable Kenya to maintain a balance between economic, socio-cultural, and environmental issues that are unique to the country's local context. Second, it should challenge the hegemony of western knowledge that has dominated Kenyan classrooms for many centuries. Finally, it should recognize the authenticity and legitimacy of indigenous knowledges and pedagogies and genuinely incorporate them into the formal educational system. The purpose of this paper is to: First explore the definition of indigenous knowledge, secondly provide a rationale for valuing indigenous knowledge in formal school system, and finally examine the dilemmas that continue to undermine and undervalue efforts to integrate indigenous knowledge in formal school curriculum in the Kenyan school system and its implications for teacher education. 
What is African Indigenous Knowledge?

Indigenous knowledge is often perceived as historical and ancient practices of the African peoples, which is a problematic perception. The word indigenous has often been used to refer to specific groups of people defined by ancestral territories, collective cultural configuration, and historical locations (Angioni, 2003; Dei, 2002; Purcell, 1998; Turay, 2002). In this context indigenous knowledge is a multifaceted bodies of knowledge, practices, and representations that are maintained and developed by peoples with long histories of close interaction with the local natural environment. The term indigenous, therefore, denotes that the knowledge is typical and belongs to peoples from specific places with common cultural and social ties. Thus, indigenous knowledge is a process of learning and sharing social life, histories, identities, economic, and political practices unique to each cultural group. This reflects the uniqueness of ways that specific societies make meaning of the world and how such forms of knowledge address local problems and solutions that are context specific. In this paper indigenous knowledge is framed as the complex set of activities, values, beliefs and practices that has evolved cumulatively over time and is active among communities and groups who are its practitioners. It remains so as long as long as the groups and communities who are its practitioners are committed to sustaining, creatively developing, and extending its potential enrichment within a specific setting.

African indigenous ways of knowing are as diverse as approximately the fortytwo ethnic communities in Kenya especially in the rural areas. Given that most of the inhabitants of Kenya live in rural areas, thus depending directly on natural resources for their livelihood, it can be inferred that indigenous knowledge systems, which relate to such resources are still very much in use and remain important to these communities. It is also important to note that such practices have evolved over time and regions, as a response of individuals and communities needs to adapt to challenges posed by their social and natural environments. As stated by Dei, Hall, and Rosenberg (2002), knowledge cannot be perceived as fixed categories, experiences, and social practices. Wane (2002) reiterates this dynamic nature of indigenous knowledge by noting that indigenous forms of knowledge have accrued over time, which is a critical aspect of cultures. Wane has argued that in the process of learning the old knowledge, new knowledge is discovered and this is what makes indigenous knowledge more dynamic. Therefore, when analysing African indigenous knowledge forms in say Kenya, there is need to realize the complexities of its evolution due to its transition, enrichment, and its devaluation during the colonial era.

Indigenous knowledge is developed and sustained through traditional education, which provides skills, trade training, and socialization avenues for many youths in Kenya today who never attended or dropped out of the formal school system. Common features in the process of knowledge transmission among most ethnic communities in Kenya occur within the context of family, community, clan tribe, and cultural age groups. It is a lifelong learning process involving progression through age groupings, seniority, and wisdom of elders (Mudimbe, 1988; Mungazi, 1996; Wangoola, 2002). Among certain ethnic groups for example the Luo's of Western Kenya, knowledge and wisdom is perceived to advance with the age of individuals based on their experiences with life. Acquisition of this form of knowledge is through interaction with daily experiences of the 
realities of the world reflecting capabilities, priorities, and value systems of members of the community.

The purpose of indigenous education is to place knowledge within the context of the user (Dei, Hall \& Rosenberg, 2002; Wane, 2002). In pre-colonial era, most Kenyan ethnic communities like other parts of Africa were guided by worldviews and value systems where spirituality became the guiding force for all human activities and development (Dei, et al, 2002; Wangoola, 2002). This is reflected in the communities' proverbs that are a source of indigenous knowledge from which we can learn or reaffirm certain valuable realities such as peace, harmony, love for life, respect for individuals, property and the environment. In this case, environmental preservation was key in human activities since the presence of God was manifest in the typology.

Indigenous education practices among Kenyan ethnic communities are holistic as it integrates all activities including rituals and skills required to sustain cultural practices, life of the family, and community. The aim is to prepare individuals for communal responsibility and interpersonal relationships as key components of the learning process. Therefore, combining specific skills acquisition with good character has been considered as virtues of being well educated and a well integrated member of the society (Mungazi, 1996; Semali, 1999). As stated by Mungazi, an individual's "place in society was determined more by his contribution to its well-being. The individual had to be trained to remain sensitive to the needs of the community as a whole and others as individuals" ( $\mathrm{p}$. 40). Cultivation of individuals' responsibilities to their communities becomes a dominant objective of the teaching and learning process in indigenous education. Among conservative communities living in rural, arid and semi-arid parts of Kenya that have not been significantly influenced by western education, individuals do have rights as individuals but primarily are held highly accountable to their communities. For example accumulation of individual property or wealth does not automatically accord status to the individual. Wealthy people who want status recognition must demonstrate their social consciousness and responsibility by contributing to their community's welfare.

Indigenous knowledge is handed down from one generation to another through symbols, art, oral narratives, proverbs, and performance such as songs, story telling, wise sayings, riddles, and dances (Dei, 2002; Mudimbe, 1988; Semali, 1999; Turay, 2002). In most rural, arid, and semi-arid parts of Kenya, especially in communities where formal education has had insignificant impact, oral art remains the most important means of transmitting knowledge and skills as a way of maintaining societal continuity from one generation to the next. For example, during initiation into adulthood among the Kikuyu, Maasai, Luhya, and Kalenjin communities, the elders prepare youths for their transitional roles and responsibilities in adulthood. In a way, this is formal education for the age sets. Methods used in indigenous education are aimed at integrating character building, intellectual training, manual activities, and physical education. Specific trade skills are learnt through apprenticeship and youths' observation of the practices modeled by adults or trainers. In the case of specialized knowledge such as indigenous medicine and spirituality, specific members of the family are identified as custodians of the knowledge and mentored through exposure to the practice by those who are specialized in the field from the family or clan (Dei, Hall \& Rosenberg, 2002; Mudimbe, 1988; Turay, 2002). Experiential knowledge is always acquired through personal exploration and practicality based on everyday lived experiences. Indigenous education involves the expertise of 
multiple teachers given the multiple natures of roles and responsibilities in life through which the youths need to be mentored and guided. This is summed up by a proverb that is commonly used across Kenyan ethnic communities, which states, "it takes a whole village to educate a child". The communal responsibility of education forms the basis for indigenous pedagogy in most Kenyan ethnic communities especially in some parts of the rural, arid, and semi-arid areas.

\section{Rationale for Valuing Indigenous Knowledge in Kenya's Formal Education}

The western concept of formal education was introduced in Kenya by the missionaries and subsequently by the colonial government. The purpose of education during the colonial period was mainly for religious conversion, economic exploitation, and the assimilation of Africans into the western cultures, values, and practices. This eroded Kenyan ethnic communities' indigenous learning structures a condition that denied individuals their cultural identity and sense of the past (Ominde, Report, 1964; Kelly \& Atbach, 1984; Ngugi, 1981; Woolman, 2001). As stated by Kelly and Atbach "education in colonies seems directed at absorption into the metropole and not separate and dependent development of the colonized in their own society and culture" (p. 4). This undermined African values, cultural practices, and imposed western capitalist mode of production, disrupting to a large extent indigenous African commerce, industry, technology, and social fabrics (Dei, 2002; Ngugi, 1981; Wangoola, 2002). Ngugi reiterates that colonial education "was far from giving people the confidence in their ability and capacities to overcome obstacles or to become masters of the laws governing external nature as human beings and tends to make them feel their inadequacies and their inability to do anything about the conditions of their lives" (p. 7). The formal western oriented education system inherited after independence not only cultivated among the elites a sense of denial to their indigenous heritage but also impacted individuals' sense of self-confidence in expressing and appreciating their native values and cultures.

It is within this background that after independence, the government of Kenya has continued the struggle to reconstruct the country's formal curricula in order to incorporate the multiple indigenous ways of knowing into the formal school system to help students develop a sense of self worth grounded in their own authentic cultural systems of knowledge construction (Ominde Report, 1964). Therefore, integration of indigenous knowledge and practices in the Kenyan education system is not then a new concept. The focus of education reforms since independence in 1963 has been to reconstruct the curriculum at all levels of the education system to reflect the diverse indigenous ways of knowing, and to promote social change and the empowerment of Kenyans (Ndegwa Report, 1971; Republic of Kenya, 2005; Ominde, Report, 1964). Reclaiming cultural identities rooted within the authentication of indigenous traditions has been perceived as a way forward to decolonizing western dominated school curricula, hence making education more relevant and practical in addressing the needs of Kenyans. An examination of education reports indicates the Kenya government's full recognition of the importance of integrating indigenous knowledge in formal education system (Ndegwa Report, 1971; Ominde Report, 1964; Republic of Kenya 1965; Republic of Kenya, 1970). The reports emphasised that one of the objectives of education system should be to respect, foster, and develop the country's rich and varied cultures. 
The objective of curriculum reconstruction has been to explore alternative solutions by utilizing local resources as a way towards addressing socio-economic and political problems that face Kenya as a country. Hence, the importance of curriculum reforms, education, and training policies aimed at integrating indigenous knowledge and western knowledge into the school system (Ominde Report, 1964; Republic of Kenya, 2005) cannot be overstated. Curriculum reconstruction process involved the inclusion of Kenyan diverse cultures, histories, geography, oral literature in high schools, and innovation in teaching that would incorporate indigenous knowledge and methods into the curriculum (Ominde Report, 1964). Mudimbe, (1988) argued that positively integrated education reforms in Sub-Saharan Africa should entail a reflection in the school curriculum that includes the history, principles, and concepts of practices, tools, and technology of communities from within the country and from other African countries. Education goals as indicated in the Kenyan policy guidelines are much oriented towards the development of an all rounded individual (Republic of Kenya, 2005).

The guiding national philosophy of African socialism and the policy of Education for Self-reliance formed the framework through which the government of Kenya framed its ideology to localize the curricula by emphasizing practical orientation especially in rural schools. The philosophy of African Socialism was based on the premise that all planning including education in post-independent Kenya must draw on the best of the African traditions and must be able to adapt to new and rapidly changing circumstances of the communities (Republic of Kenya, 1965). The framework for integrating indigenous knowledge in the education curriculum was articulated in the first Kenyan education report developed after independence (Ominde Report, 1964), which basically was guided by the national philosophy of African socialism as stipulated in the Sessional Paper No 10 of 1965. This report formed the basis for policy frameworks that has guided curriculum innovations and education change at all levels to date. The formulation of this report was based on the premise that education needed to be more accessible and relevant to the social, economic, and political needs of students and their communities. Therefore, integrating African indigenous knowledge and ways of teaching and learning has been perceived as necessary in de-emphasizing the current curriculum that has been viewed to be too abstract, not relevant, and more examination oriented.

Curriculum reconstruction in post-colonial Kenya became part of the process aimed at reclaiming cultural identity with deeper roots in authenticating African traditions. The main concern of the government has been the empowerment of the citizens through the social, economic, and national reconstruction of the society (Republic of Kenya, 2005). Education has since then been perceived to function as an agency of cultural transmission, economic, and political development. Thus, the education system in Kenya is expected to play a mediating role in the relationship between the diverse cultures, the national culture, and the global needs of the nation (Lillis, 1985; Ominde Report, 1964; Republic of Kenya, 2005; Semali, 1999; Kenyatta, 1965). Jomo Kenyatta, the first president of Kenya viewed education as a tool for maintaining the traditional structures of family, kinship, gender, and age groupings as another way of ensuring the stability of African ethnic communities (Kenyatta, 1965). Without stability of these communities through the process of education, Kenyatta foresaw the onset of the disintegration of the social systems. In his book facing Mount 
Kenya, Kenyatta advised teachers: "To promote progress and preserve all that is best in the traditions of the African people and assist them in creating a new culture, which through its roots are still in the soil, is yet modified to meet the pressure of modern conditions" (p. 123). This reflects the perceived value of education as a way to achieving a holistic approach to the societal development at the face of changing times.

The current global discourse on the value of incorporating indigenous knowledge in formal education systems in Sub-Saharan African countries, has been a central theme by scholars, African governments, and the United Nations Organizations (Angioni, 2003; Dei; 2002; Government of Kenya, 2005; Purcell, 1998; Semali, 1999; UNESCO, 2006) particularly its potential contribution to sustainable development at the micro level and poverty alleviation. It is argued that if African states are to play a central role in directing the goals of education for sustainable development, then there is need to integrate the African perspectives of knowledge as a reciprocal body of knowledge to western education in order to ensure relevance and practicality in addressing local problems affecting societies especially the devastating effects of HIV/AIDS pandemic (Dei, 2002; Mudimbe, 1988; Shiva, 2002; UNESCO, 2006). According to these studies and report, problems afflicting the African continent and Kenya in particular, are based on complex realities that not only can but also should be approached at different levels (macro and micro) and by employing different methods and forms of knowledge. Dei intimates that in order for local governments and international communities to find solutions to socioeconomic problems facing African states, there is a need to explore the contribution of the culturally based knowledge resources as alternatives to local sustainable development. This requires understanding the capability of indigenous knowledges in the development process of communities, and ways in which indigenous people strategise their own survival within specific settings.

\section{Issues to Consider When Integrating Indigenous Knowledge in the Curriculum}

Despite the stated value and potential of indigenous knowledge in providing solutions to some of the problems inflicting Kenya's communities, educators need to examine what implications the inclusion of this form of knowledge has for pedagogy and its sustainability in the current classroom settings. This is because of the diverse nature of Kenya's ethnic communities and centuries of dominance of the country's education system by western epistemologies. First, educators and curriculum developers need to be cautious and avoid bundling together the diverse Kenyan ways of knowing under one category of indigenous knowledge. This is because such generalization may lead to separating these forms of knowledge from their specific contexts (Angioni, 2003, Semali, 1999), a condition that may lead to oversimplication and superficial implementation. Also, such homogenization is likely to jeopardize the potentially unique and important contribution that specific forms of indigenous knowledge can make to development within specific localities and among local groups who embrace such knowledge.

At the same time educators need to recognize the fact that the uniqueness of indigenous knowledge in a particular culture does not necessarily mean that there is internal consensus or that all members of the same ethnic group adhere to the same knowledge base in their socio-economic and political decision-making process. Given the current acculturation and development of cosmopolitan communities (Makhubu, 
1998; Semali, 1999) individual members perceptions may differ significantly on specific ways of doing things. Central questions that need to be explored when integrating indigenous knowledge in the curriculum reforms are: What aspects of indigenous knowledge need to be incorporated in the integration process? What related features of indigenous ways of knowing and modes of learning are common across the diverse Kenyan indigenous cultures and which ones are unique to particular ethnic groups? Answers to these questions would act as a guide to identifying those features of indigenous knowledge that can be made visible during the process of curricula development.

Secondly, most Kenyan indigenous education systems are highly hierarchical, hence top-down diffusion of knowledge becomes the norm, creating unequal power relations between those in subordinate positions of authority such as in the case of teachers and students (Scott \& Miller, 2002). Therefore, students and teachers may find themselves in situations of dilemmas and contradictions due to conflicting value orientations based on their perceptions of knowledge construction. For example, African students who have been immersed within a conservative cultural setting that value authority of elders may find it challenging to express divergent views from their teachers, hence limiting the process of dialogue in the classroom and instead promoting the authoritarian and what Friere (1994) refers to as the banking models of teaching. Yet students living in cosmopolitan settings who have been exposed to western perspectives through the media and information technologies bring into the classroom a more critical perspective to learning. This might not be appreciated by conservative teachers who maintain traditional beliefs on the central role of teachers in the legitimacy of knowledge construction based on their cultural beliefs on ownership of knowledge and authority in the classroom. This normally results in conflict with conservative teachers not being able to promote democratic classroom environments limiting analytical and critical thinking among students, which should be key ingredients to education process.

Thirdly, the western-based schooling system recognizes teachers' professionalism as central in facilitating the process of classroom knowledge construction. This does not provide any space for classroom dialogue in which the experiences of members of local communities such as the role of elders can be incorporated in formal classroom knowledge construction. Yet African indigeneity cultivates respect for the authority of knowledge of community elders due to their wisdom, accumulated knowledge, and their closeness to the ancestral world (spirituality) (Dei, 2002; Mudimbe, 1988). Such knowledge based on intuition and experiences of life have been devalued as lacking in scientifically based methods and findings from empirical research. This poses challenges to the current debates of endogenous approach to education, which features discourses on possibilities of effective involvement of indigenous community members in the integration of indigenous knowledge into the formal education system (Mwenda, 2003; Semali, 1999; UNESCO, 2006) as facilitators of the learning process.

Fourthly, indigenous knowledge is highly engendered and therefore, men and women usually have different and often complimentary societal roles and responsibilities resulting in different social constraints. If educators do not examine this aspect of indigenous knowledge, there is likelihood that the integration may override the ongoing government's efforts and strategies aimed at addressing gender disparities through incorporating gender inclusive pedagogy and curriculum in the school system. Thus, 
despite the Kenya government's commitment to integrating indigenous knowledge in the formal school curriculum, the process has been faced with a lot of challenges as discussed in the following section.

\section{Challenges to Integrating Indigenous Knowledge in Formal Education in Kenya}

At independence, integrating indigenous knowledge in a British structured model of education created great challenges to Kenyan policymakers and implementation process due to limited capacity of indigenous teachers and curriculum developers. This was because as at that time of Kenya's independence in 1963, the impact of indigenous teaching force had not evolved sufficiently to create a critical mass of African educators who were equipped with the right skills and knowledge to support the process of curriculum change (Lillis, 1985; Ominde Report, 1964). This was compounded by the fact that the colonial government did not see the need to train indigenous educators especially for secondary schools given their focus of education for economic exploitation. As stated by Abdi (2006) "colonial programs of education were designed and put into place to maximize all possible returns for colonialism" (p. 21). Thus, lack of capacity of trained indigenous educators became a hindrance to the curriculum implementation.

Hence the dominance of foreign teachers in post-colonial education system under the auspices of British aid to education, continued to influence the process of curriculum innovations posing great challenges to the indigenization of the Kenyan school curriculum (Lillis 1985). Lillis asserts that, "as teachers, course writers, project developers, disseminators, and inspectors of schools, expatriate educationists dominated these areas of curriculum while Africans played a subordinate role" (p. 80). Thus, the absence of indigenous personnel to take charge of their own curriculum reconstruction process meant continued presence of foreign assumptions about what constituted valid school knowledge and valid means of assessing such knowledge (Mwenda, 2003; Lillis, 1985). Therefore, implementing the stated education objective of integrating African indigenous knowledge within the curriculum was superficial. An example is the inherited British education system at the secondary school level that was based on the Cambridge Examinations and certification. This was examined in the United Kingdom until 1968 when the East African Examination Council (EAEC) was formed (Woolman, 2001). Despite the formation of an East African examining body, the curriculum was still modeled around the Cambridge Examination of the United Kingdom and continued to be manned by expatriates, mainly from Britain, who ensured the dominance of a European curriculum in the Kenyan education system.

In other instances where positions of educational decision-making process had been Africanized such as the political and civil service, the dominant presence of elites who are products of and valued western conceptualizations of knowledge preferred to maintain the status quo (Lillis, 1985; Mwenda, 2003; Ngugi, 1981; Woolman, 2001). The Kenyan elites visualized western education and Eurocentric modernization as having potential for economic development and a way forward to industrialization and economic progress. Thus, the western mode of economic development was accorded more preference over indigenous modes of economic development by ensuring a continued reliance on macro planning. This approach ignored local conditions, local development needs, and the role of indigenous knowledge in developmental activities within regions 
such as rural, arid, and semi-arid areas of Kenya, which basically relies in this form of knowledge (Makhubu, 1998; Semali, 1999). Moreover, most elites did not wholly embrace their cultural heritage, given their aculturalization of western values that influenced their focus towards nationalistic perceptions of cultural development rather than solving economic problems at the local and communal levels.

The interface between school and indigenous knowledge apparently has created a lot of dilemmas and contradictions for Kenyan educators and policy-makers. The dilemmas have been on how to achieve the targeted integration, a condition that requires the involvement and commitment of all stakeholders of education. These include the policy makers, teachers, educators, parents, and community members who might not necessarily hold common perspectives on the value of indigenous knowledge in addressing issues of socio-economic development (Dei, 2002; Mwenda, 2003; Lillis, 1985; Republic of Kenya, 2005). Therefore, lack of consensus in recognizing and validating the contribution of indigenous knowledge, practices, and innovation remains a challenge to achieving successful practically oriented relevant educational changes that addresses the needs of learners and their communities. The genesis of all this can be viewed in the light of Kenya's experiences with colonial education where such forms of knowledge were delegitimized and devalued.

The idea of organized curricula based on a highly western economic model, contradicts the traditional approach in which learning is basically integrated into the communities' socio-economic activities (Mwenda, 2003; Republic of Kenya, 1998). Incorporating indigenous knowledge and pedagogy into the formal schooling therefore involves confronting power, authority and prestige of the existing western dominant culture and destabilizing the status quo (Angioni, 2003; Dei, 2002; Semali; 1999), a condition that is likely to create dilemmas and challenges for teachers, educators, and curriculum developers given their western oriented education background. Thus, an overarching socio-economic issue that Kenya shares with other Sub-Saharan countries is the challenge of modernizing the society by integrating indigenous traditions of knowledge that is largely based on subsistence economy and local specificities with the western development model with its reliance on market forces and western epistemologies.

Other challenges to the integration process arise from the complex nature of indigenous knowledge and practices, which involve their incorporation into individuals' way of life, making it invisible, hence not easy to identify the components to be implemented in innovations (Semali, 1999; Mwnenda, 2003; Woolman, 2001; Republic of Kenya; 2005). The invisibility is due to its embeddedness into the day-to-day socioeconomic activities. For example, among the Luo of Western Kenya, emphasis in indigenous education is placed on learning by doing through repeated practice over time rather than observation and replication. Thus, the knowledge is passed on in the context of personal relationships between the learners and mentors actively involved in the everyday interaction with the natural environment and activities necessary for survival. Individuals are practically engaged in activities such as fetching firewood, water, gardening, construction, trades, herding cattle, and physical activities among other things. Today one can argue that in most Kenyan communities, there are fewer adults who posses the skills that need to be passed on to the youth that would support the capacity for integration of indigenous knowledge in formal education. At the same time the move 
among young people away from hereditary activities has made transmission and impartation of indigenous knowledge impersonal and disembodied from context. Disembodiment of indigenous knowledge is as a consequence of the replacement of traditional local authorities, demographic changes, urbanization, technological changes, modernization, commercialization, commodification of living resources, and the policies of external assistance agencies. These forces continue to pressurize the world to adopt western perspectives to the detriment of indigenous ways of knowing, practice, and technology.

The national dependency syndrome on external donors to support education reforms also contradicts education policies in the reform process. Dependence on foreign assistance to support Kenyan education reforms has led to education policies being influenced by external agents, forcing the government to focus on meeting the goals of globalization above the local needs and interests. Therefore, attracting donor funding to support research in education that would provide adequate information for implementation of the integration of indigenous knowledge in formal education has suffered setbacks (Gachanga, 2007; Lillis, 1985; Mwenda, 2003; Republic of Kenya, 1998). In most cases donors are inclined toward the support of research in education that is based on their conception of what constitutes education or what they validate as important topics and approaches to education. Yet findings from such forms of research are not likely to provide relevant information that would appropriately support the integration of indigenous knowledge into the formal school curriculum. As stated by Gachanga :

Despite acknowledgement of the important role indigenous knowledge plays in sustainable development and peace building, many governments, donors, and NGOs appear to make little use of this valuable resource. Their recognition of indigenous knowledge often amounts to little more than lip service, seldom translating into action or funding (p. 11).

This has resulted in lack of empirical studies to provide informed policy decisions and resource deficiency limiting the development of learning materials and professional development, which are key components for successful curriculum transformation (Government of Kenya, 1998). An example is the superficial implementation of the local languages as a medium of instruction in the lower levels of elementary schools, which continue to be positioned in subordination to foreign languages such as English and Kiswahili in the classroom as a medium of instruction.

The Kenya government's efforts to incorporate indigenous knowledge into the formal education curriculum in the post-colonial era has partly been aimed at confronting power, authority, and prestige of western knowledge which subordinates indigenous forms of knowledge in formal schooling. This approach is one of the ways in which the government has tried to empower its citizens to take control of their own development (Ominde Report, 1964). Incorporating indigenous knowledge in formal education signifies the recognition of the power of the role of both the individual and collective agency of change that is found in the potential of using multiple forms of knowledge in solving current problems inflicting Kenyan communities. The pluralistic approach to knowledge systems requires that different forms of knowledge and methods be 
authenticated and embraced in the school system and that no one system be used as a benchmark for other knowledge forms (Mwenda, 2003; Semali, 1999; Shiva, 2002). Yet the integration takes place in the school environment that already privileges western epistemologies against indigenous epistemologies, a condition that continues to create hegemony in Kenya's school knowledge construction. This has often created contradictions between what is intended by the curriculum reforms and what is actually implemented in classrooms, resulting in incongruence between students' indigenous experiential knowledge and formal school knowledge (Mwenda, 2003; Semali, 1999; Woolman, 2001). Therefore, attempts to indigenize the curriculum in Kenya have met with little success and have been implemented superficially.

Among all the pervasive forces is the legacy of colonialism that peripherally influences theories of knowledge construction and development of education programs in former colonized countries. Thus, Eurocentric values continue to dominate the Kenyan school system, creating contradictions to traditional values, as the priorities of scientific methods, research, and development dominate the knowledge construction process that inform Kenyan education practices. As stated by Abdi (2006) "the expansion of western formal education created a situation where traditional education in colonized societies was portrayed by colonial powers as ineffective in managing the lives and welfare of colonized peoples and communities" (p. 18). This is because knowledge hegemony constructs dominance and sustains power inequalities privileging and promoting cultural capital of the dominant western knowledge (Dei, et al, 2002; Ngugi, 1981) privileged by Kenyan elites who are the policy makers, curriculum developers, and implementers. At the same time, education stakeholders such as parents, curriculum developers and policy makers, have difficulty coping with the demands and obligations of indigenous practices visa vie expectations of emerging global economies, commercialization and commodification of knowledge which acts as a force in defining Kenyan education policies.

The dominating belief that prosperity means westernized development and western education continues to undermine the authenticity and legitimization of indigenous ways of knowing in Kenya's formal education (Mwenda, 2003). As stated by Mwenda, what results is a "system of education that is in itself a form of governmentality... where the individuals absorb dominant ideologies that construct imaginary pictures of prosperity that are shaped by foreign styles" (p. 216). This indicates how teachers, educators, and curriculum policy makers who embrace western perspective of what constitutes valid knowledge are likely to discern indigenous values, knowledge, and methods of teaching or may embrace it superficially, enabling the dominance of western values to take precedence. Therefore, the legacy of colonialism continues to prevail upon Kenya's educational and economic growth creating the need to change the discourse on indigenous knowledge especially with regards to indigenous education versus western ways of knowing. Revitalizing the value of indigenous knowledge through curriculum reforms are vital if communities are to engage in sustainable economic development that is oriented to their local needs (Dei, 2002; Mudimbe, 1988; Mwenda, 2003; Shiva, 2002). This becomes necessary if Kenya and other Sub-Saharan countries are to reshape their own education framework in order to determine terms of development within the macro and micro levels.

The on-going global focus on knowledge commodification promotes competition, 
contradictions, and dilemmas for educators and teachers in the implementation of the integration of indigenous knowledge into the curriculum. At the same time the interface between school and indigenous knowledge is rarely a focus for most Kenyan educators and policy makers. Unfortunately the transfer of indigenous knowledge from everyday life to schoolwork is not always valued or recognized by teachers (Dei, 2002; Mwenda, 2003; Semali, 1999), and it is therefore necessary for teacher education programs to rethink ways in which to prepare teachers for effective integration of multiple forms of knowledge when designing and implementing the teacher education curriculum.

\section{Implications for Teacher Education}

Teachers' attitudes toward and beliefs about the value and potential contribution of indigenous knowledge to sustainable development define how they integrate this form of knowledge into the formal school curriculum (Gachanga, 2007). Some of the challenges in the integration of indigenous knowledge in formal education arise from teachers' lack of faith that such a curriculum can actually contribute significantly in addressing the socio-economic needs of the country (Dei, 2002; Gachanga, 2007; Mwenda, 2003; Semali, 1999). Teachers' inability to integrate indigenous knowledge in their practice may also be resulting from limited knowledge on what aspects to integrate. Somjee (1996) noted that although teachers are entrusted with the responsibility of fostering indigenous knowledge in the learning institutions of Kenya, "there is no guidance on what aspects of culture are to be integrated into the curricula. The syllabus only tells teachers what they must do and should do, but not explain how to do it" (p.6), indicating the limitations that Kenyan teachers are bound to phase when implementing such a curriculum.

In teacher education this means preparing pre-service and in-service teachers to reflect on their own philosophies of education and ways in which these values support or inhibit their ability to integrate multiple ways of knowing and methodologies into their own classroom practices (Dei, 2002; Mwenda, 2003; Semali, 1999; UNESCO, 2006). The focus is for teachers and teacher educators to adopt practices that embrace both western and indigenous knowledge in ways that defy dichotomous presentation, foster relevance, inculcate a sense of self-worth, and national pride among learners. As teachers and educators develop a more culturally inclusive curriculum practices, they must confront the emerging challenges from within themselves and the environment in which they are operating.

In order for educators and teachers to effectively integrate indigenous knowledge into curriculum content, there is a need to transform individuals' perceptions of what constitutes legitimate and valuable school knowledge, learning, and teaching. Teachers and educators need to examine their practices and develop ways to authentically engage and legitimise indigenous knowledge forms into the formal education system. As Mwenda (2003) asserts, "it is time that Kenyan educators come to the realization that western diagnosis for development does not reflect Africa's realities" (p. 222). The purely western models of education and economy are not capable of addressing the current socio-economic problems at the micro level, especially in the rural regions of Kenya. Hence, there is a need to revitalize the presence of ethnic indigenous ways of knowing, pedagogy and practices in the educational system if Kenyans are to redefine 
and re-shape their own socio-economic framework within their own terms of development at the micro level.

In problematizing what has been accepted in Kenya's schools as universal valid knowledge and standards for industrialization and economic development (Dei, 2002; UNESCO, 2006), the following questions would form aspects of a useful guide: What knowledge is of worth and in whose interest does the knowledge operate? How can indigenous knowledge and pedagogy be integrated in a reciprocatory way with western knowledge in the formal school system? Who counts as experts or innovators in this process? It is only when educators and teachers address such questions critically that they may empower themselves and in turn be able to empower students' knowledge construction by building on indigenous knowledge base that students bring with them into the classroom settings. Unfortunately many teachers and educators still privilege western ways of knowing and interpretation of the world over indigenous knowledge especially in the face of globalisation (Dei, et al, 2002; Shiva, 2002).

Thus, to complement the integration of indigenous knowledge in formal education, it is important to inquire into educators' and teachers' perceptions of indigenous knowledge with a view to understanding their capability in developing appropriate pedagogical approaches and materials for implementation of such curriculum reforms. The pluralistic approach to knowledge systems requires educators to embrace their own logic and epistemological foundations and acceptance that one system of knowledge cannot act as a standard of measure for all knowledge systems.

\section{Conclusion}

Indigenous knowledge has now become the central issue in global discourses as a strategy to solutions on social, economic, and political problems of African states of which Kenya is part. Endogenous approach to Education for Sustainable Development advocates for educational process that is based on a holistic perspective, practically based, and conceptualized to the local, national, and international needs of the students. The purpose is to establish an appropriate balance between African cultures, knowledge, values, economic needs, social pressures, demands of the national, and localized and global development strategies. UNESCO (2006) expresses the need for a more participatory approach to education that involves communities in decision-making based on the understanding of the principles of sustainable development. Part of what is stressed in these is the incorporation of cultural heritage and values as the grounding for education, perpetuated through indigenous languages as and transmission of indigenous knowledge. Diversity of knowledge should be valued and need not be reduced to the standards and epistemology of western perspective of knowledge base.

Unless disciplines taught and methodologies adopted reflect genuine commitment to the integration of indigenous knowledge, acceptance of multiple perspectives of knowledge in the curriculum, and encouragement of local community inputs, school knowledge will continue to be abstract, and irrelevant to the Kenyan students' needs. The process of decolonization of school knowledge requires that the African peoples confront the claim that outsiders have the knowledge and abilities to better understand their needs and shape the direction of their own development process. In this paper I have argued that to avert the current economic marginalization, education stakeholders 
such as policy makers, educators, teachers, curriculum developers, and parents through the process of education should inculcate into our children the virtue of taking lead in their own construction of knowledge based on their local experiences. It is only through playing leading roles in shaping their own destiny in development of their communities that Kenyan students can be able to appreciate working with outsiders in a reciprocal way with the understanding that both parties have knowledge that can be shared and valued.

This will create a process through which African indigenous knowledges can also be seen to contribute to knowledge systems on social and environmental sustainability. Ironically, awareness of the value of indigenous knowledge, particularly its potential contribution to sustainable development and poverty alleviation is growing at a time when such knowledge is being threatened by the domination of knowledge commercialization and commodification. The current global knowledge commodification promotes competition and hegemony that has a long history of dominating qualities against the indigenous knowledge perceived to lack authority and power due to its intuitive nature that is argued to have no scientific basis. Therefore, educators and teachers as curriculum implementers need to problematize what has been accepted in schools as universal valid knowledge or in the case of economic development as standards of measure for industrialization and economic growth.

The pluralistic approach to knowledge systems requires that all stakeholders of education respect the diverse knowledge systems, embrace their logic, and epistemological foundations. This should also involve acknowledging the value, reciprocal relations, and contributions of all forms of knowledge to the global body of ways of knowing. Understanding of the Kenyan ethnic communities past and present indigenous practices provides positive perspectives about groups sustainable economic and social responsibilities. This can form part of the approaches to sustainable development by inculcating values that promote communal solidarity in order to protect the environment, natural resources, and address current prevailing social issues inflicting communities' due to HIV/AIDS and poverty. 


\section{References}

Abdi, A.A. (2006) Eurocentric discourses and African philosophies and epistemologies of education: Counter-hegemonic analyses and responses. International Education 36 (1), 15-29

Angioni, G. (2003) Indigenous Knowledge: Subordination and Localism. In G. Sanga \& G. Ortalli (Ed), Nature, Knowledge: Ethnoscience, cognition, and utility (pp. 287296). New York: Oxford.

Dei, S.G. J, Hall. B.L. \& D.G. Rosenberg, D.G (2002) Indigenous knowledges in global contexts: multiple readings of our world. Toronto: University of Toronto Press.

Dei, S.G.J. (2002). African development: The relevance and implications of indigenousness. In G.J.S. Dei, B.L. Hall, \& D.G. Rosenberg (Ed), Indigenous knowledges in global contexts: Multiple readings of our world (pp. vii-x). Toronto: University of Toronto Press.

Gachanga, T. (2007) Education for peace in Kenya: Indigenous peace traditions and the Millennium Development goals. Retrieved on $29^{\text {th }}$ September, 2007 from http//www.africafiles.org/atissueezine.asp.

Kelly, G.P. \& Atbach, P.G. (1984) The four faces of colonialism. In G.P. Kelly \& P.G. Atbach (Ed), Education and the colonial experience (pp. 1-5). Brunswick: Transaction.

Kenyatta, J. (1965) Facing mount Kenya: The tribal life of the Gikuyu. NY: Vintage Books.

Lillis, K.M. (1985). Africanizing the school literature curriculum in Kenya: A case study in curriculum dependency. Journal of Curriculum Studies, 18 (1), 63-84.

Makhubu, L. (1998). Essays on science and society, bioprospecting in an African context. Journal of Science, 282 (5386), 41-42.

Mudimbe, V.Y. (1988). The invention of Africa: Gnosis, philosophy, and the order of knowledge: Gnosis, philosophy, and the order of knowledge. Indianapolis, IN: Indiana University Press.

Mungazi, D.A. (1996) The mind of black Africa. London: Prague.

Mwenda, N. (2003) The challenges of education and development in post-colonial Kenya. Africa Development, 28, 3-4

Ndegwa Report (1971) Report of the commission of enquiry. Nairobi: Government Printers.

Ngugi, W.T. (1981) Decolonizing the mind: The politics of language in African literature. Portsmith, NH: Heineman.

Ominde Report (1964) The Kenya education commission report part 1. Nairobi: Government

Purcell, T.W. (1998) Indigenous knowledge and applied anthropology: Questions of definition and direction. Human Organization, 57 (3), 258-272.

Republic of Kenya (1965) African socialism and its application to planning in Kenya. Nairobi: Government Printers.

Republic of Kenya (1970) Development plan 1970-74. Nairobi: Government Printers.

Republic of Kenya (1998) Master plan on education and training 1997-2010. Nairobi: Government Printers. 
Republic of Kenya (2005) Sessional paper no. 1: A policy framework for education, training and research. Nairobi: Ministry of Education Science and Technology.

Scott, D.J. \& Miller, A.N. (2002) A cross-cultural study of immediacy, credibility, and learning in the U. S. and Kenya. Journal of Communication Education, 51 (3), 280-292.

Semali, L. (1999) Community as Classroom: Dilemmas of Valuing African Indigenous Literacy in Education. International Review of Education, 45 (3), 305-319.

Shiva, V. (2002) Foreword: Cultural diversity and the politics of knowledge. In G.J.S. Dei, B.L. Hall, \& D.G. Rosenberg (Ed), Indigenous knowledges in global contexts: Multiple readings of our world (pp. vii-x). Toronto: University of Toronto Press.

Somjee, S. H. (1996) Learning to be indigenous or being taught to be a Kenyan: The ethnography of teaching art and material culture in Kenya. Unpublished thesis. Montreal: McGill University.

Turay, T. M. (2002) Peace research and African development: An indigenous African perspective. In G.J.S. Dei, B.L. Hall \& D.G. Rosenberg (Ed), Indigenous knowledges in global contexts: Multiple readings of our world (pp. 248-263). Toronto: University of Toronto Press.

UNESCO (2006) Strategy of Education for Sustainable Development in Sub-Saharan Africa. UNESCO Regional Office for Education in Africa: UNESCO/BREDA.

Wane, N. N. (2002) African women and spirituality: Connection between thought and education. In E. O'Sullivan, A. Morrell, \& M. O'Connor (Eda.), Expanding the boundaries of transformative learning: Essays on theory and praxis (pp. 135150). New York: Palgrave, St. Martin's Press.

Wangoola, P. (2002) Mpambo, the African multiversity: A philosophy to rekindle the African spirit. In G.J.S. Dei, B.L. Hall \& D.G. Rosenberg (Ed), Indigenous knowledges in global contexts: Multiple readings of our world. Toronto, ON: University of Toronto Press.

Woolman, D.C. (2001) Educational reconstruction and post-colonial curriculum development: A comparative study of four African countries. International Education Journal, 2 (95), 27-46. 